\title{
A Downscaling Approach for SMOS Land Observations: Evaluation of High-Resolution Soil Moisture Maps Over the Iberian Peninsula
}

\author{
María Piles, Member, IEEE, Nilda Sánchez, Member, IEEE, Mercè Vall-llossera, Senior Member, IEEE, Adriano Camps, \\ Fellow, IEEE, José Martínez-Fernández, Justino Martínez, and Verónica González-Gambau
}

\begin{abstract}
The ESA's Soil Moisture and Ocean Salinity (SMOS) mission is the first satellite devoted to measure the Earth's surface soil moisture. It has a spatial resolution of $\sim 40 \mathrm{~km}$ and a 3-day revisit. In this paper, a downscaling algorithm is presented as a new ability to obtain multiresolution soil moisture estimates from SMOS using visible-to-infrared remotely sensed observations. This algorithm is applied to combine 2 years of SMOS and MODIS Terra/Aqua data over the Iberian Peninsula into fine-scale $(1 \mathrm{~km})$ soil moisture estimates. Disaggregated soil moisture maps are compared to $0-5 \mathrm{~cm}$ ground-based measurements from the REMEDHUS network. Three matching strategies are employed: 1) a comparison at $40 \mathrm{~km}$ spatial resolution is undertaken to ensure SMOS sensitivity is preserved in the downscaled maps; 2 ) the spatiotemporal correlation of downscaled maps is analyzed through comparison with point-scale observations; and 3) high-resolution maps and ground-based observations are aggregated per land-use to identify spatial patterns related with vegetation activity and soil type. Results show that the downscaling method improves the spatial representation of SMOS coarse soil moisture estimates while maintaining temporal correlation and root mean squared differences with ground-based measurements. The dynamic range of in situ soil moisture measurements is reproduced in the highresolution maps, including stations with different mean soil wetness conditions. Downscaled maps capture the soil moisture dynamics of general land uses, with the exception of irrigated crops. This evaluation study supports the use of this downscaling approach to enhance the spatial resolution of SMOS observations over semi-arid regions such as the Iberian Peninsula.
\end{abstract}

Index Terms-Dissagregation, downscaling, Moderate resolution Imaging Spectroradiometer (MODIS), REMEDHUS, Soil Moisture and Ocean Salinity (SMOS), soil moisture.

Manuscript received October 28, 2013; revised May 07, 2014; accepted May 07, 2014. This work is supported by the Spanish Ministry of Science and Innovations through the projects AYA2010-22062-C05 and AYA201239356-C05.

M. Piles, M. Vall-llossera, and A. Camps are with the Remote Sensing Laboratory/IEEC, Universitat Politècnica de Catalunya, E-08034 Barcelona, Spain, and also with the SMOS Barcelona Expert Center (SMOS-BEC), 08003 Barcelona, Spain (e-mail: maria.piles@tsc.upc.edu).

N. Sánchez is with the Centro Hispanoluso de Invetigaciones Agrarias (CIALE), Universidad de Salamanca (USAL), 37185 Villamayor, Spain, and also with the Departamento de Ingeniería Cartográfica y del Terreno, USAL, 05003, Ávila, Spain.

J. Martínez-Fernández is with the Centro Hispanoluso de Invetigaciones Agrarias (CIALE), Universidad de Salamanca (USAL), 37185 Villamayor, Spain, and also with the Departamento de Geografía, USAL, 37002 Salamanca, Spain.

J. Martínez and V. González-Gambau are with the Departamento de Oceanografía Física y Tecnológica, Institut de Ciències del Mar, CSIC, and also with the SMOS-BEC, 08003 Barcelona, Spain.

Color versions of one or more of the figures in this paper are available online at $\mathrm{http}: / /$ ieeexplore.ieee.org.

Digital Object Identifier 10.1109/JSTARS.2014.2325398

\section{INTRODUCTION}

$\mathbf{S}$ OIL MOISTURE is the state variable that links the Earth's water, energy, and carbon cycles. It controls evaporation and transpiration at the land-atmosphere boundary, and plays an important role in determining the amount of runoff, and therefore the likelihood of droughts and floods that may affect an area. Changes in soil moisture affect the evolution of weather and climate over continental regions. This explains why knowledge of soil moisture is important for numerous applications, including water resources management, agricultural productivity estimation, ecological modeling, and early warning systems [1]. However, measuring soil moisture is challenging, specially because of its high variability across temporal and spatial scales [2], [3]. Even though it is possible to estimate mean soil moisture over large areas using point-scale in situ measurements [4], [5], remote sensing is the only practical means to obtain regionaland global-scale soil moisture estimates, especially where no prior information is available.

Theoretical and experimental evidence have suggested that L-band radiometry is optimal for soil moisture sensing, since at these frequencies: 1) soil emissivity is very sensitive to the presence of liquid water in the soil; 2) the atmosphere is nearly transparent; and 3) the vegetation is semi-transparent up to moderate densities [6]. As a result, the first two satellite missions ever designed to measuring this variable have an L-band radiometer on-board: the European Space Agency (ESA) launched the Soil Moisture and Ocean Salinity (SMOS) mission in November 2009 [7], [8], and the U.S. National Aeronautics and Space Administration (NASA) plans to launch the SMAP mission in 2014 [9]. Still, due to practical constraints on antenna size and altitude of low Earth orbits, the spatial resolution of SMOS and SMAP radiometers is limited to 40-50 km. This resolution serves for global-scale applications, but is too coarse for regional and local scale studies where (at least) $1-10 \mathrm{~km}$ are needed. Options to bridge this gap include the use of alternative remote sensing techniques and the development of pixel disaggregation techniques to enhance the spatial resolution of the radiometric observations.

The main alternative technologies to L-band radiometry for soil moisture remote sensing are the use of higher frequency radiometers, the use of active sensors (radars and scatterometers), and the use of visible/infrared sensors. However, as it will be discussed hereafter, they all suffer from some drawback that limit their applicability. Microwave radiometers working at 
This article has been accepted for inclusion in a future issue of this journal. Content is final as presented, with the exception of pagination.

C- and X-bands have a high sensitivity to soil moisture, but at these frequencies the atmosphere is more opaque-its effects need to be corrected for-soil penetration depth is $\operatorname{lower}(\sim 1 \mathrm{~cm}$ vs. $\sim 5 \mathrm{~cm}$ at L-band), and soil emission is highly attenuated by vegetation. Radars operating at L-band, in turn, are capable of sensing surface characteristics at typically high spatial resolution ( $\sim 1 \mathrm{~km}$ or even higher with synthetic aperture processing), but radar backscatter is influenced to a great extent by combined effects of water content, surface roughness, vegetation, topography, and vegetation canopy structure, which hampers soil moisture retrievals. Also, radars typically operate with narrow beams, meaning that they do not meet the temporal requirements of land hydrology applications ( $\sim 3$ days). The scatterometers onboard the European Remote Sensing (ERS) and the METeorological OPerational (METOP) satellites have been proved useful to detect soil moisture changes with time using a soil moisture index [10], but its spatial resolution is limited to $\sim 25 \mathrm{~km}$. In this regard, visible/infrared sensors offer a wide suite of spatial, spectral, and temporal resolution combinations, from a spatial resolution of several tens of meters and 16-day revisit time for Landsat and advanced spaceborne thermal emission and reflection radiometer (ASTER) to $1 \mathrm{~km}$ and daily observations for MODerate resolution Imaging Spectroradiometer (MODIS). However, reflected solar radiation is not a particularly feasible technique for directly measuring soil moisture [11], even though there is some research in this direction [12]-[14]. Commonly, visible/infrared sensors are used to provide an indirect measurement of soil moisture in combination with microwave sensors data [15]-[17], but not to retrieve it. Besides, observations in the optical domain have the handicap of being totally masked in presence of cloud cover.

Due to the above-mentioned advantages and disadvantages of current technology for soil moisture sensing, it seems natural to try to develop multisensor/multiresolution disaggregation techniques that permit to obtain remotely sensed soil moisture estimates at different spatial scales. This has been the motivation for a number of recent studies dedicated to enhance the spatial resolution of SMOS and upcoming SMAP radiometric observations. SMAP will have a high-resolution radar on-board to enhance the spatial resolution of soil moisture estimates up to $10 \mathrm{~km}$. Hence, the use of temporal covariations of active and passive data is the central approach to SMAP dissagregation [18], [19]. For SMOS, combination with kilometric optical data seems to be the most promising strategy [20]-[22]. A methodology to convert optical-derived evaporation efficiency to surface's soil moisture using different semiempirical calibrated models was proposed in [20]. Comparison of disaggregated soil moisture against $1 \mathrm{~km}$ aggregated in situ measurements, acquired during two field experiments in South-Eastern Australia, showed the quality of the soil moisture estimates is highly dependant on the season. A mean spatial correlation coefficient of 0.7 was reported during the summer experiment and of 0 during the winter one [20], which is consistent with the weaker coupling between evaporation and surface moisture in a semiarid climate. The capability of downscaling SMOS soil moisture estimates to $100 \mathrm{~m}$ using a two-step approach-first downscaling SMOS soil moisture using MODIS and next downscaling MODIS-disaggregated soil moisture using 15-day revisit ASTER - is presented in [22]. These results may suggest the performance of optical-based disaggregation methodologies rely on the atmospheric evaporative demand, with varies greatly across seasons, and particularly leads to noisy estimates in winter periods. However, as it will be discussed later in this paper, this may not be the case when disaggregation approaches are not based on evaporation efficiency and, more importantly, it needs to be confirmed using longer time series of downscaled soil moisture maps and in situ data.

This paper is devoted to a long-term validation of a microwave/optical disaggregation approach to optimally blend SMOS polarimetric observations with fine-scale MODIS visible/infrared data into high spatial resolution soil moisture maps. This downscaling scheme was first presented in [21] along with results of its application to a set of SMOS images acquired during the commissioning phase over the Oznet network, SouthEast Australia. Soil moisture variations quantified in terms of standard deviation and root mean square differences (RMSDs) were resolved at spatial scales of 1 and $10 \mathrm{~km}$, in general agreement with aggregated in situ data. The model linking the spatial scales in [21] is composed by nonlinear interaction terms relating optical and radiometric data. Using reprocessed SMOS data obtained with improved L1 and L2 processors, further development and validation of this technique have resulted in a fine-tuned and more robust model. It linearly relates the two instruments across spatial scales and benefits from SMOS polarimetric and multiangular information [23]. To date, validation results from comparison with in situ data over a selected suite of representative sites support the use of this downscaling method; high-resolution soil moisture maps are shown to nicely reproduce soil moisture dynamics at MODIS spatial resolution $(1 \mathrm{~km})$ while keeping SMOS sensitivity $\left(0.04 \mathrm{~m}^{3} / \mathrm{m}^{3}\right)$. The algorithm is implemented at SMOS-BEC facilities and highresolution soil moisture maps over the Iberian Peninsula are daily generated and distributed in near real time (NRT) to meet the needs of early warning and meteorologic systems [24]. In this study, the temporal and spatial variability of 2 years of disaggregated soil moisture estimates over the Iberian Peninsula is evaluated through comparison with ground-based measurements acquired at the in situ soil moisture measurement network (REMEDHUS) located in the central part of the Duero basin, Spain. This network has shown a high performance in validation and applications activities with passive microwave sensors [25], active [26], and both of them [27], all devoted to soil moisture retrieval.

The paper is organized as follows. Data sets as well as methods used for comparison to ground-based measurements are described in Section II. An overview of the downscaling technique is presented in Section III. Validation results are presented in Section IV. A comparison at $40 \mathrm{~km}$ is performed to ensure SMOS sensitivity is preserved with the proposed technique. Spatio-temporal correlation of downscaled maps is analyzed by comparison with point-scale measurements, and land use clustering is used to identify spatial patterns. Results are presented separately for SMOS ascending/descending passes and for MODIS Terra/Aqua land surface temperature (LST). In Section V, the main findings of this paper are discussed and the conclusions and perspectives are presented. 


\section{DATA AND MeTHODS}

\section{A. In Situ Soil Moisture Data}

Ground-based measurements of $0-5 \mathrm{~cm}$ volumetric soil moisture from the REMEDHUS permanent soil moisture monitoring network, in the central semi-arid sector of the Duero basin, Spain, are used to evaluate the algorithm performance. REMEDHUS is equipped with 19 soil moisture stations and 4 automatic weather stations deployed over an area of $35 \times 35 \mathrm{~km}$ $\left(41.1^{\circ}-41.5^{\circ} \mathrm{N} ; 5.1^{\circ}-5.7^{\circ} \mathrm{W}\right)[25]$. The distribution of the stations is irregular, based on the distribution of the main physiographic and pedological units of the area. All stations are considered to be hydrologically independent even though they are all included within the same climatic context, the continental Mediterranean climate. The annual precipitation was 510 and $290 \mathrm{~mm}$, for 2010 and 2011, respectively. The land uses are mainly agricultural, with rainfed cereals grown in winter and spring, irrigated crops in summer, and vineyards in summer-fall. There are also mixed forest-pasture areas. In [25], 1 year of SMOS L2 soil moisture data was shown to compare well with REMEDHUS in situ ground measurements. No differences were reported between the use of time-overpass values of in situ soil moisture or the use of daily averages for the comparison. Based on these results, in situ daily averages will be used in this study to compare with satellite morning and afternoon passes.

\section{B. Remotely Sensed Data}

In its current form, the downscaling algorithm only requires SMOS and MODIS remotely sensed data for implementation. Two years of collocated SMOS and MODIS observations over the Iberian Peninsula have been selected for this study, from March 1, 2010 to February 29, 2012. For validation purposes, in situ soil moisture observations from REMEDHUS stations during this period have been collected and a land use map is extracted from a multitemporal series of Deimos-1 imagery [28].

SMOS, Terra, and Aqua are low Earth orbiting satellites with local equatorial crossing times of approximately 6 A.M./ 6 P.M. for SMOS, 10:30 P.M./10:30 A.M. for Terra, and 1:30 P.M./1:30 A.M. for Aqua, in ascending/descending nodes. In this study, SMOS ascending passes are combined with MODIS Terra/Aqua descending passes (morning passes), and SMOS descending passes are combined with MODIS Terra/Aqua ascending passes (afternoon passes). It is therefore assumed that the soil moisture pattern is spatially persistent for a few hours before and after the SMOS overpass. Only days with cloud free MODIS LST over REMEDHUS during the study period are considered. This results in a total of 365 SMOS-Terra and 374 SMOS-Aqua morning passes, and of 406 SMOS-Terra and 407 SMOS-Aqua afternoon combinations.

Details on data sets, preparation, and methodologies are presented as follows.

1) SMOS: SMOS L1C version 504 brightness temperatures $\left(T_{B}\right)$ are used to derive horizontal and vertically polarized $T_{B}$ maps at incidence angles $\theta_{i}$ of $32.5^{\circ}, 42.5^{\circ}$, and $52.5^{\circ}$. These maps are estimated through chi squared linear fit of all $T_{B}$ values included in the $\theta_{i} \pm 5^{\circ}$ interval, which is the methodology used to generate the SMOS L1C browse product [29]. Surface level $T_{B}$ maps are then obtained by correcting ionospheric (geometric and Faraday rotations) and atmospheric effects. SMOS L2 version 500 soil moisture data is used as benchmark soil moisture at a $40-\mathrm{km}$ scale. The resolution of SMOS observations varies from $30 \mathrm{~km}$ at nadir to $\sim 90 \mathrm{~km}$ at the upper borders of the field-ofview. In this paper, SMOS brightness temperatures and soil moisture estimates are resampled from the ISEA4h9 grid to a regular grid of $0.25^{\circ}$ and are combined with MODIS data into downscaled 1-km spatial resolution soil moisture maps.

Since its launch, SMOS data have suffered contamination from on-ground man-made sources of radio frequency interference (RFI). The areas affected by RFI experience either an underestimation in the retrieved geophysical parameter or data loss. Even though the L-band is protected, approximately 500 RFI sources distributed worldwide have been detected, most of them located in Asia and Europe. Currently, the situation has improved in Europe, where half of the active sources have been switched off [30]. In this study, detected RFIs which contaminated SMOS data have been screened out.

2) MODIS: The MODIS sensor operates on both the Terra and Aqua spacecrafts. The MODIS products used in this paper are the version 5 MODIS/Terra and MODIS/Aqua $1-\mathrm{km}$ resolution daily LST and MODIS/Terra 1-km resolution 16day Normalized Difference Water Index (NDVI) product (data sets MOD11A1, MYD11A1, and MOD13A2, respectively). Daily LST observations are masked by the presence of clouds, whereas the NDVI composite is cloud-free. The MODIS reprojection tool is used to convert from sinusoidal to geographical projection as well as to perform the mosaicking of the four tiles covering the Iberian Peninsula. MODIS data is freely distributed by the U.S. Land Processes Distributed Active Archive Center (lpdaac.usgs.gov).

3) Deimos-1: The satellite Deimos-1 is the first Spanish Earth observation satellite, launched in 2009 to join the disaster monitoring constellation (DMC). Even though the small satellites of this constellation were designed for emergencies and resources monitoring purposes, DMC imagery is especially suitable for large-area land cover mapping because of its $600-\mathrm{km}$ swath width and its revisit time of 2-3 days [31]. The on-board sensor in Deimos-1 has three bands (G, R, NIR) and 22-m spatial resolution. The processing level is LT-1, corresponding to ortorectified images (RMSD $<10 \mathrm{~m}$ ) and values of 8 bitscaled radiances. The scaled radiances were first transformed into radiances using the gain and bias values, and next into reflectances following the approach of [32] and applying the Chance-Kuruk spectrum [33] for the solar irradiance model. Finally, the NDVI was calculated as the normalized difference between the reflectances of infrared and red bands.

Six images were provided from July 2010 to September 2011, comprising the growing cycle of the main crops in the agricultural area of REMEDHUS. This period is chosen to avoid crops changing in the study area. The composite image of the six NDVIs is the input for the classification, based on a hybrid vector-raster segmentation method [34]. This method isolates the less changing categories (forest-pasture, vineyard, unproductive, and water) by means of the vector information from the geographic information system (GIS) for Agricultural Plots of 
Castilla y León Region. Areas of rainfed, irrigated, and fallow uses were segmented based on their different NDVI evolution, taking advantage of the opposite growing cycle of all of them. Next, they were converted to polygons prior to overlapping them with the soil moisture maps. An accuracy assessment with 167 ground truth areas showed an $89 \%$ averaged coincidence for all the categories.

\section{Matching Strategies}

A variety of performance metrics have been proposed for the validation of footprint-scale satellite retrievals of geophysical variables using point-scale measurements. In particular, the challenge of validating satellite retrievals of surface (top $5 \mathrm{~cm}$ ) soil moisture has received considerable attention [25], [35], [36]; there are still unresolved issues concerning the representativeness of point-based observations and the appropriateness of different upscaling techniques [37]. Also, no single metric or statistic can capture all the attributes of environmental variables, being each metric robust with respect to some attributes and relatively insensitive or incomplete with respect to others [38].

Metrics such as bias, RMSD, slope of linear regression, and time series correlation (R) are often used to assess the accuracy of geophysical retrievals (satellite measurements) with respect to ground-based observations. Although RMSD is extensively used as target accuracy for satellite geophysical retrievals, this quantity is severely compromised if there are biases in either the mean or the amplitude of fluctuations in the retrieval. The unbiased RMSD (ubRMSD) can then be used to reflect the RMSD of soil moisture anomalies that are computed by removing the mean temporal soil moisture. In this paper, the abovementioned metrics are used to assess the performance of the downscaling algorithm when using morning/afternoon orbits and Terra/Aqua MODIS platforms, in the course of 2 years. Note that, since in situ data contain errors (instrumental and representativeness), they are not considered as "true" soil moisture. This is underlined here by using RMSD terminology instead of RMS error.

A regional-scale validation exercise is performed first to ensure the $40-\mathrm{km}$ scale mean of the original SMOS L2 product is conserved in the downscaled maps. A comparison at high resolution is performed next, where statistics of the comparison of SMOS L2 and SMOS downscaled versus in situ measurements from individual REMEDHUS stations are reported. Temporal correlations and RMSDs for the 2 years of data are presented. To further examine the soil moisture variability resolved at high resolution, both a seasonal analysis and a spatial comparison per land use are performed using a hydrological year (from September 1, 2010 to September 30, 2011). The Deimos-1-derived land use map is overlapped with the fine-scale soil moisture maps, and the spatial average of the pixels enclosed within each land use category is calculated. Accordingly, the in situ stations are averaged upon their land-use (seven stations of vineyard, six of rainfed crops, three of fallow, one irrigated, and two of forest-pasture). Time series of SMOS downscaled and in situ soil moisture data aggregated per land use are obtained; statistical scores as well as visual and qualitative results are analyzed.

\section{Downscaling Algorithm}

The downscaling approach for SMOS used in the present paper is an upgraded version of the algorithm in [21]. It is based on a model - a regression formula - that links SMOS $T_{B}$, MODIS NDVI and MODIS LST to soil moisture and holds at the two spatial scales under consideration, i.e., SMOS $40 \mathrm{~km}$ and MODIS $1 \mathrm{~km}$. In [23], it was shown that including SMOS polarimetric and multiangular information in the model resulted in a more robust coefficient determination and more accurate soil moisture estimates. Based on these results, the following linear linking model is used in this paper to relate the two instruments across spatial scales

$$
s_{m}=a_{0}+a_{1} \cdot T_{N}+a_{2} \cdot F_{N}+\sum_{i=1}^{3} a_{3 i} \cdot T_{B H \theta_{i} N}+\sum_{i=1}^{3} a_{4 i} \cdot T_{B V \theta_{i} N}
$$

where $s_{m}$ stands for soil moisture, $T_{N}$ and $F_{N}$ are normalized LST and NDVI, respectively, and $T_{B H \theta_{i} N}$ and $T_{B V \theta_{i} N}$ are normalized horizontal and vertically polarized $T_{B}$, respectively, at incidence angles $\theta_{i}$ of $32.5^{\circ}, 42.5^{\circ}$, and $52.5^{\circ}$. Normalization of each variable $X$ in (1) is performed between the minimum $X_{\min }$ and maximum $X_{\max }$ values obtained for a particular morning/afternoon pass and scene (in this study: $34^{\circ}-45^{\circ} \mathrm{N}$, $\left.11^{\circ} \mathrm{W}-5^{\circ} \mathrm{E}\right)$ :

$$
X_{N}=\frac{X-X_{\min }}{X_{\max }-X_{\min }} .
$$

Parameters in the model are represented in both a low-and a high-spatial resolution grid: $T_{N}$ and $F_{N}$ are linearly aggregated to $40 \mathrm{~km}$ and $T_{B H \theta_{i} N}$ and $T_{B V \theta_{i} N}$ are resampled at $1 \mathrm{~km}$. The model is first applied at low resolution using SMOS Level 2 soil moisture as a $40-\mathrm{km}$ soil moisture reference; a system of linear equations is set up using all the pixels of a specific morning/ afternoon pass and scene, and model fitting coefficients $a_{k}$ are obtained by the least squares method. Then, the model is applied at high resolution using the obtained coefficients to get the disaggregated soil moisture.

This downscaling scheme is the operational algorithm used at SMOS-BEC to generate $1-\mathrm{km}$ spatial resolution soil moisture maps over the Iberian Peninsula (L4 product). Maps from years 2010 to 2013 downscaled using MODIS/Terra LST can be freely accessed through SMOS-BEC data distribution and visualization service (cp34-bec.cmima.csic.es). Global SMOS data as well as MODIS data over the Iberian Peninsula is received in NRT at SMOS-BEC facilities and, since June 2012 the downscaling algorithm is triggered twice a day, corresponding to SMOS ascending and descending passes to serve high-resolution soil moisture maps in NRT (delay of $<12 \mathrm{~h}$ ) [24]. As a prime NRT application, these maps are being used by local fire prevention services in their early warning system to detect extremely dry soil and vegetation conditions posing a risk of fire.

\section{RESULTS}

\section{A. Regional-Scale Validation}

An image of SMOS data disaggregated at $1 \mathrm{~km}$ compared with SMOS L2 data over the Iberian Peninsula (from November 4, 

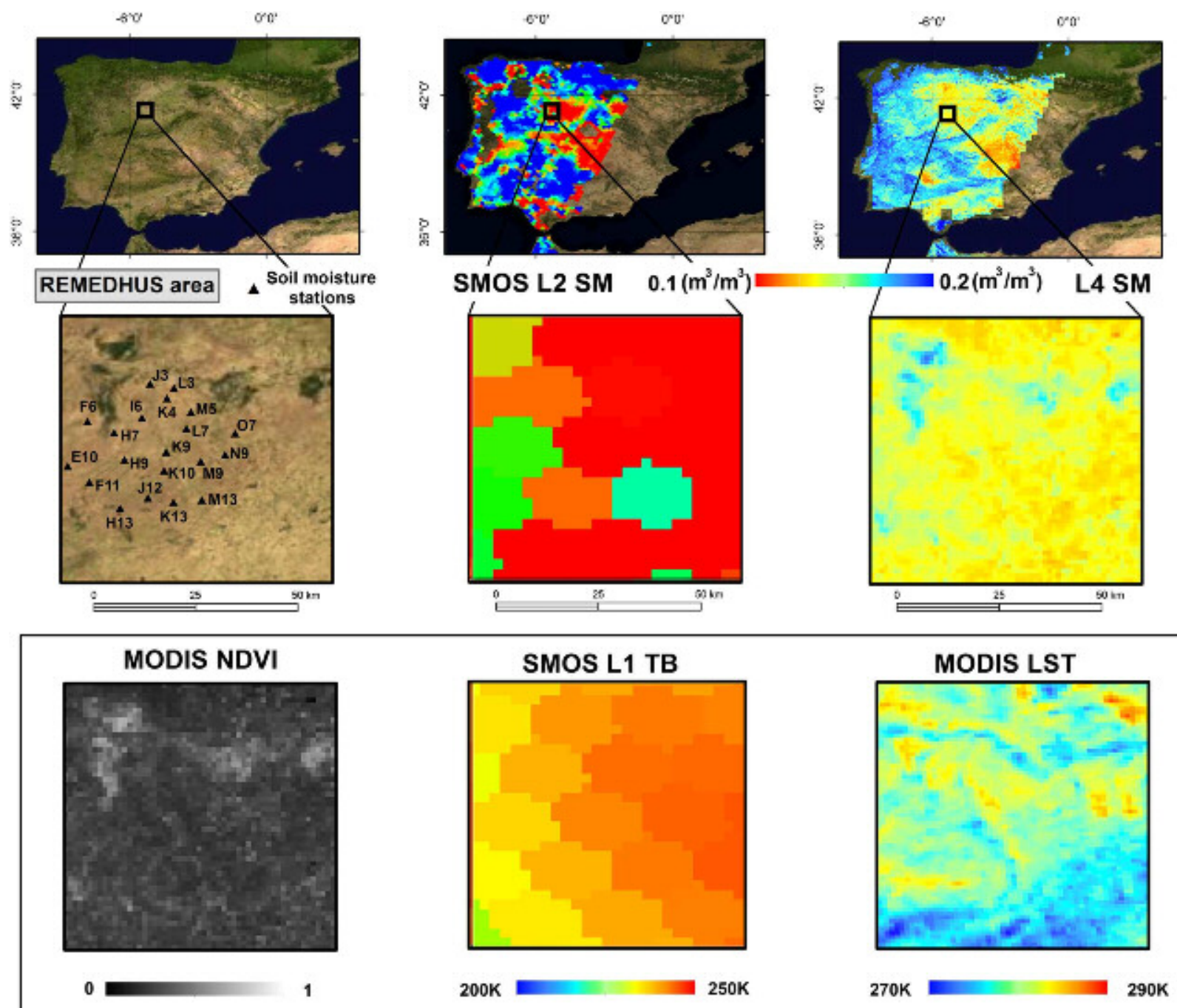

200K

$250 K$

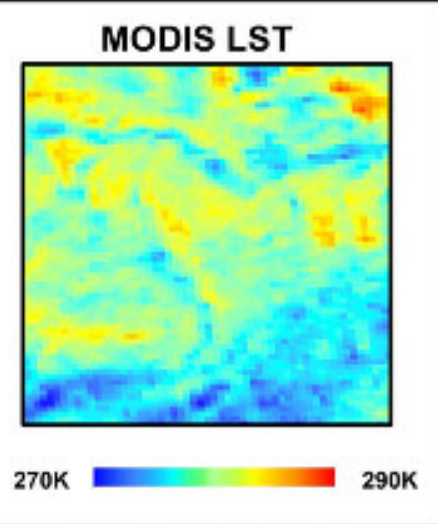

Fig. 1. First two rows contain images of Landsat RGB composite (left), SMOS L2 soil moisture (center), and SMOS data disaggregated at 1 km (right) over the Iberian Peninsula (first row) and REMEDHUS (second row), from November 4, 2010, afternoon pass. The layout of permanent stations within REMEDHUS is overlayed to the Landsat composite. The third row contains the MODIS/Terra NDVI (left), SMOS L1C horizontal $T_{B}$ at $42.5^{\circ}$ (center), and MODIS/Terra LST (right) from the same day, used to generate the soil moisture map at $1 \mathrm{~km}$.

2010) is shown in Fig. 1, where the REMEDHUS area is detailed. The SMOS L1 horizontal $T_{B}$ at $42.5^{\circ}$ incidence angle, MODIS/ Terra NDVI, and LST from that day over REMEDHUS are also displayed. Information on the spatial distribution of soil moisture within coarse-scale radiometric pixels can be observed in the SMOS disaggregated maps, consistent with the patterns present in MODIS LST and NDVI data. Note the method uses all the pixels of a given scene having SMOS L1, SMOS L2, and 40-km aggregated NDVI and LST to determine the model coefficients. However, once the model is built, high-resolution soil moisture maps are obtained by applying (1) using NDVI, LST and 1-km resampled SMOS L1 (data within the rectangle in Fig. 1). Hence, high-resolution soil moisture data can be generated in areas where there is SMOS L1 data, but SMOS L2 is not available (i.e., soil moisture at low resolution cannot be retrieved from brightness temperatures with the required accuracy). Then, although SMOS L2 data is used to calibrate the model at lowspatial resolution, areal averages of SMOS, and of 1-km disaggregated soil moisture may differ. Also, when adjusting the linking model between spatial scales, we are assuming a certain chi-squared error. This error must be quantified to ensure the average of the estimated high-resolution soil moisture matches that of the low-resolution observation. In particular, comparing low-and high-resolution soil moisture maps in Fig. 1, it can be seen that the soil moisture content is higher in the SMOS disaggregated than in the SMOS L2. This higher soil moisture content is consistent with the mean ground-based soil moisture recorded on REMEDHUS stations for that day, which is $0.134 \mathrm{~m}^{3} / \mathrm{m}^{3}$ (corresponding to yellowish coloring).

A comparison at $40 \mathrm{~km}$ between SMOS L2, SMOS downscaled, and in situ SM has been performed. Ground-based observations are aggregated using linear spatial averaging. The temporal evolution of these three soil moisture time-series over REMEDHUS is shown in Fig. 2. It shows that ground-based soil moisture temporal dynamics are captured by the downscaled soil moisture estimates at a regional scale. Areal-averaged downscaled estimates match well with in situ data (circles and triangles are enclosed within the network's soil moisture variability in shaded green). It can be noted that better results are obtained with downscaled maps from afternoon passes [(Fig. 2(c) and (d)]; they 


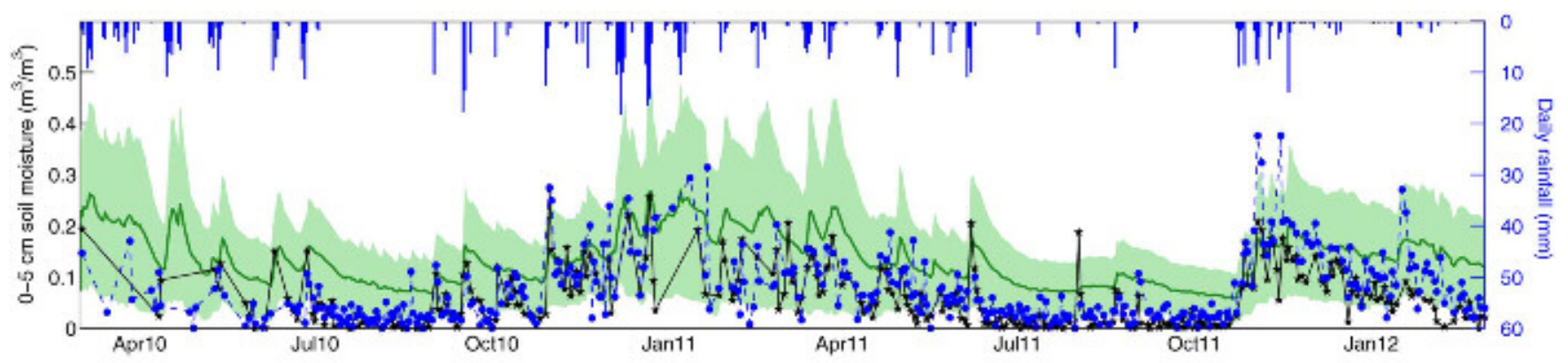

(a)

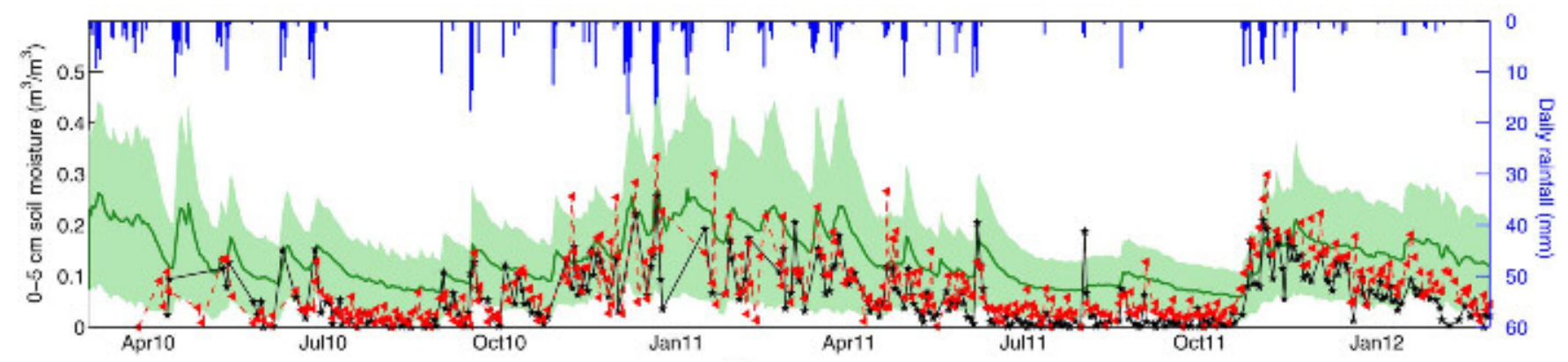

(b)

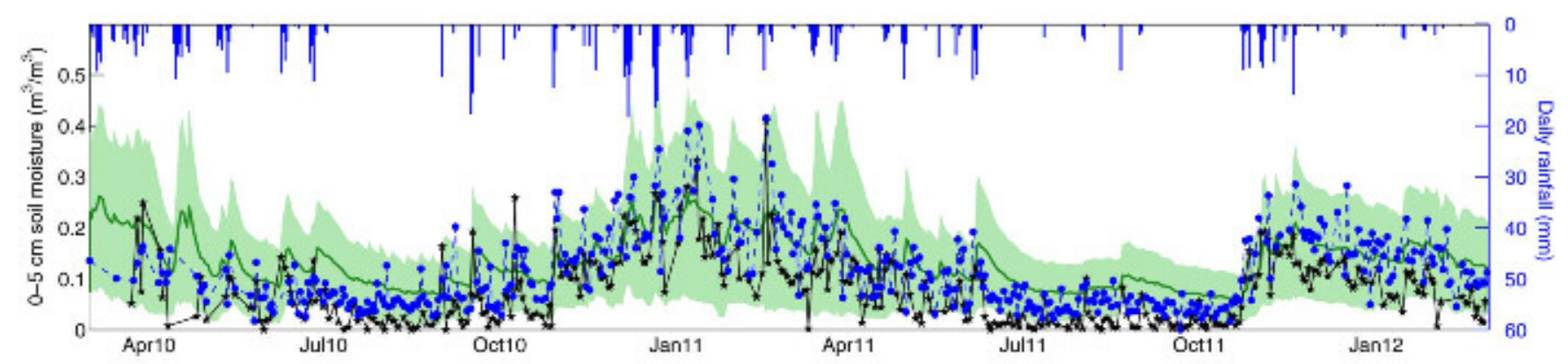

(c)

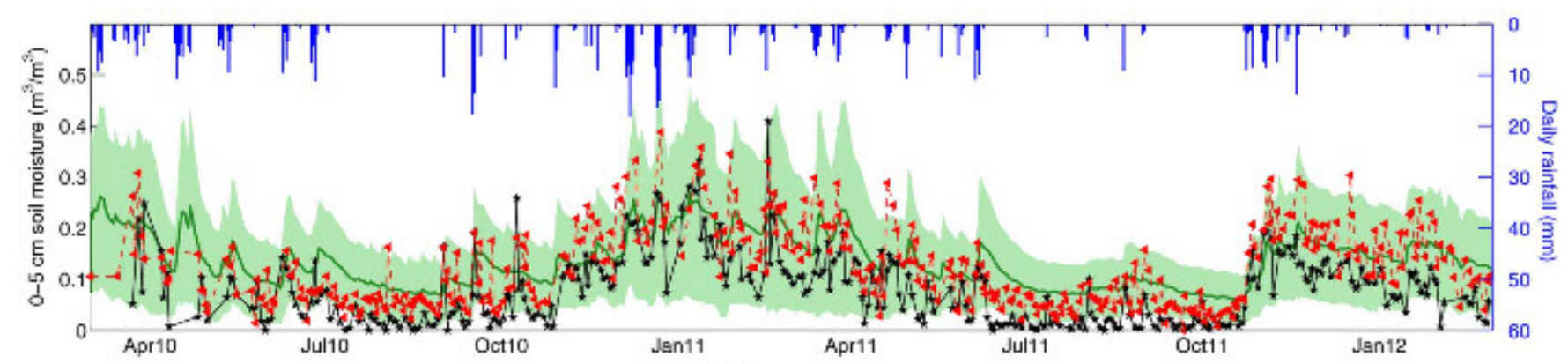

(d)

Fig. 2. Temporal evolution of surface soil moisture time-series over REMEDHUS: ground-based mean (green solid line) and standard deviation (green shaded areas), SMOS L2 (black stars), 40-km aggregated SMOS-Terra downscaled (red triangles), and 40-km aggregated SMOS-Aqua downscaled (blue circles). Daily mean rainfall on top of each plot. (a) SMOS-Aqua morning passes. (b) SMOS-Terra morning passes. (c) SMOS-Aqua afternoon passes. (d) SMOS-Terra afternoon passes.

closely track ground-based average soil moisture and also compensate for the dry bias present on SMOS L2 data. Results over additional validation sites are needed to assess whether the method is capable of compensating for SMOS L2 systematic biases.

Main statistics on the comparison between SMOS L2 and areal-averaged SMOS disaggregated with soil moisture measurements are reported in Table I. Scores confirm that SMOS sensitivity is preserved at low resolution when downscaling: areal-averaged downscaled maps maintain SMOS L2 errors and correlation to in situ data, with $\mathrm{R}$ of $\sim 0.4 / 0.6$ for morning/ afternoon passes, and ubRMSD of $\sim 0.03-0.04 \mathrm{~m}^{3} / \mathrm{m}^{3}$. The bias on SMOS L2 is actually reduced in the downscaled maps, with an improvement of $\sim 0.01-0.02$ in the RMSD. For afternoon passes, measures of skewness (S) and kurtosis (K) evidence that the downscaled estimates are closer to a normal distribution than SMOS L2 data (S closer to 0, K closer to 3). Also, slightly better results in terms of $\mathrm{R}, \mathrm{S}$, and $\mathrm{K}$ are obtained 
TABLE I

Statistics of 2 Years of Daily Areal Averages of SMOS and 1-km Disaggregated Soll Moisture Versus Ground-Based Soll Moisture Measurements Over REMEDHUS

\begin{tabular}{lcccccccc}
\hline & $\begin{array}{c}\mathrm{R} \\
(-)\end{array}$ & $\begin{array}{c}\text { Slope } \\
(-)\end{array}$ & $\begin{array}{c}\text { Bias } \\
\left(\mathrm{m}^{3} / \mathrm{m}^{3}\right)\end{array}$ & $\begin{array}{c}\mathrm{stdev} \\
\left(\mathrm{m}^{3} / \mathrm{m}^{3}\right)\end{array}$ & $\begin{array}{c}\text { RMSD } \\
\left(\mathrm{m}^{3} / \mathrm{m}^{3}\right)\end{array}$ & $\begin{array}{c}\text { ubRMSD } \\
\left(\mathrm{m}^{3} / \mathrm{m}^{3}\right)\end{array}$ & $\begin{array}{c}\mathrm{S} \\
(-)\end{array}$ & $\begin{array}{c}\mathrm{K} \\
(-)\end{array}$ \\
\hline $\begin{array}{l}\text {-Morning orbits: } \\
\text { SMOS L2 }\end{array}$ & 0.50 & 0.89 & -0.07 & 0.04 & 0.08 & 0.03 & 0.77 & 5.23 \\
$\quad \begin{array}{l}\text { Downscaled Aqua } \\
\text { Downscaled Terra }\end{array}$ & 0.40 & 0.88 & -0.05 & 0.05 & 0.07 & 0.03 & 1.35 & 7.93 \\
-Afternom orbits: & 0.41 & 0.87 & -0.04 & 0.05 & 0.07 & 0.03 & 0.83 & 5.56 \\
$\quad$ SMOS L2 & 0.58 & 1.01 & -0.06 & 0.04 & 0.07 & 0.03 & 1.28 & 7.12 \\
$\quad \begin{array}{l}\text { Downscaled Agua } \\
\text { Downscaled Terra }\end{array}$ & 0.57 & 1.15 & -0.02 & 0.05 & 0.05 & 0.04 & 0.87 & 4.75 \\
\hline
\end{tabular}

Correlation coefficient (R), slope of linear regression, mean difference (Bias), mean standard deviation (Stdev), root mean square difference (RMSD), unbiased RMSD (ubRMSD), skewness (S), and kurtosis (K).

using MODIS/Terra than using MODIS/Aqua to downscale SMOS TBs.

\section{B. Spatial Comparison at High Resolution}

A spatial comparison at high resolution of downscaled soil moisture estimates with in situ measurements has been performed to analyze spatio-temporal correlations of disaggregated maps. Statistics of the comparison at each REMEDHUS station are reported in Fig. 3. As a reference, results of comparing SMOS L2 against individual stations have also been included. Bar graphs reflect that spatial patterns are captured at $1 \mathrm{~km}$, with $\mathrm{R}$ of $\approx 0.3-0.7 / 0.4-0.8$ for morning/afternoon passes, RMSD of $\approx 0.05-0.24 / 0.05-0.20 \mathrm{~m}^{3} / \mathrm{m}^{3}$ and ubRMSD of $\approx 0.03-0.10 / 0.03-0.09 \mathrm{~m}^{3} / \mathrm{m}^{3}$. With SMOS L2 data, the same ranges are obtained in terms of R and ubRMSD, whereas the RMSD is generally higher (up to $0.027 \mathrm{~m}^{3} / \mathrm{m}^{3}$ ). This indicates the dry bias present on SMOS L2 data is reduced in the downscaled maps, in-line with areal-average results in Table I and Fig. 2. It can be noted that stations J12, M13, and H9 exhibit a particularly high RMSD. Stations M13 and H9 are located in valley bottoms, flooded-prone areas; this explains their high bias. Station J12, in turn, changed from rainfed to fallow in the study period. Results on irrigated lands exhibited nonsignificant correlations with p-values $>0.05$ (not shown). In line with areal-averaged results, better results are obtained with afternoon than with morning orbits, and better temporal correlations are obtained when using Terra than when using Aqua LST.

A seasonal analysis has been performed focused on 1 year of measurements covering a complete hydrologic cycle (from September 1, 2010 to September 30, 2011). Scatter plots of Fig. 4 display the agreement between remotely sensed soil moisture and REMEDHUS in situ time-series for this period, with segments illustrating the linear fit of seasonal data. Comparisons between SMOS L2 and in situ point-scale measurements (left column), and between 1-km soil moisture and in situ point-scale measurements (right column) are shown for representative stations of higher water content (first row, forest pasture), very low water content (second row, vineyard) and intermediate water content (third row, rainfed cereals). The comparison between SMOS L2 and the selected REMEDHUS stations shows a near-zero or even negative slope for the linear fit, illustrating a certain underestimation previously observed in the area [25]. On the contrary, scatter plots of 1-km soil moisture versus in situ point-scale measurements showed a significant increase in the slope. In general, disaggregated maps show an improved slope on the linear correlation (close to the 1:1 line) in stations with intermediate water content, underestimate soil moisture in stations of high water content (slopes $\sim 0.2-0.4$ ), and overestimate soil moisture in stations of very low water content (slopes $\sim 0.6-0.8$ ). Results on Fig. 4 indicate the performance of the proposed methodology is not highly seasonally dependent, as opposed to other LST/NDVI-based disaggregation approaches which report noisy estimates in winter periods [20].

The computation of spatial correlation at a daily scale was not satisfactory for a sufficient number of days (only 36 clear-sky days had daily correlations with statistical significance at a $95 \%$ level). Correlation values on these days are low (from 0.2 to 0.5 ), what suggests that the temporal variations on soil moisture are better reproduced at high resolution that spatial patterns. However, this aspect should be analyzed in future investigations for instance with dedicated field experiments undertaking intensive and distributed sampling of soil moisture or using land surface models.

\section{Spatial Patterns Using Land-Use Clustering}

Disaggregated soil moisture maps for selected dates covering the seasonal cycle of vegetation are presented in Fig. 5. Plots are for July 27, 2010 (summer), November 11, 2010 (autumn), February 17, 2011 (winter), and April 15, 2011 (spring). The map from Deimos-1 is included to identify the different land covers at the 1-km scale; the annual evolution of the mean precipitation and mean soil moisture of the in situ measurements per land use is also included. Note that soil moisture maxima contents in the maps of Fig. 5 are adjusted per season in order to represent the whole variability of the data, as indicated in the colorbars.

Statistical results from the comparison of downscaled pixels and REMEDHUS stations aggregated per land-use for the hydrological year starting in September 2010 are reported in the bar graphs on Fig. 6. As expected, results using land-use clustering are consistent with those obtained by the the point-scale and areal-averaged comparisons: best results in terms of R and RMS errors are obtained with the data set of afternoon orbits and better correlatioins are obtained using Terra than Aqua LST data.

Spatial details can be detected in the downscaled maps, related with the growing cycle of the vegetation covers and the seasonal 

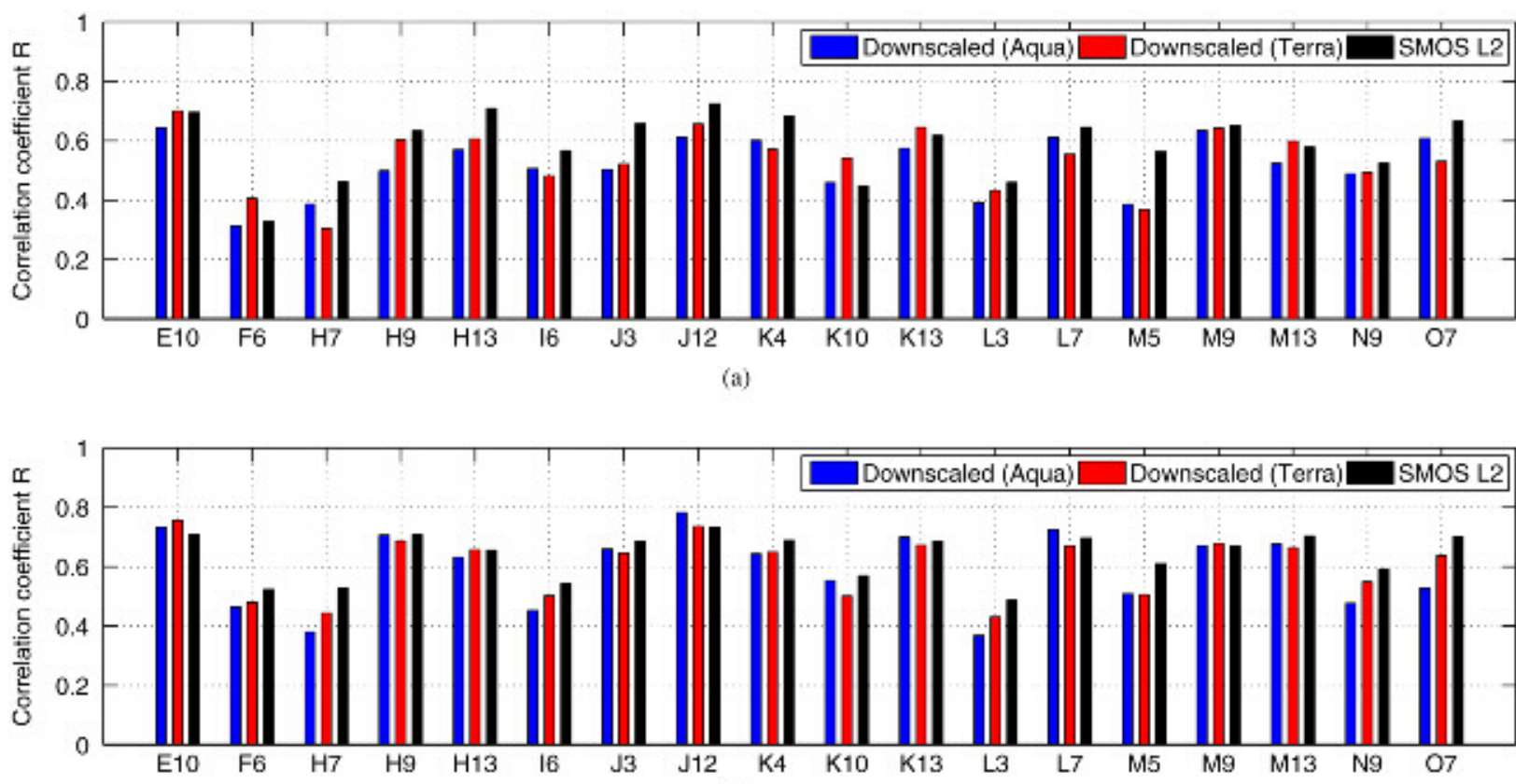

(b)
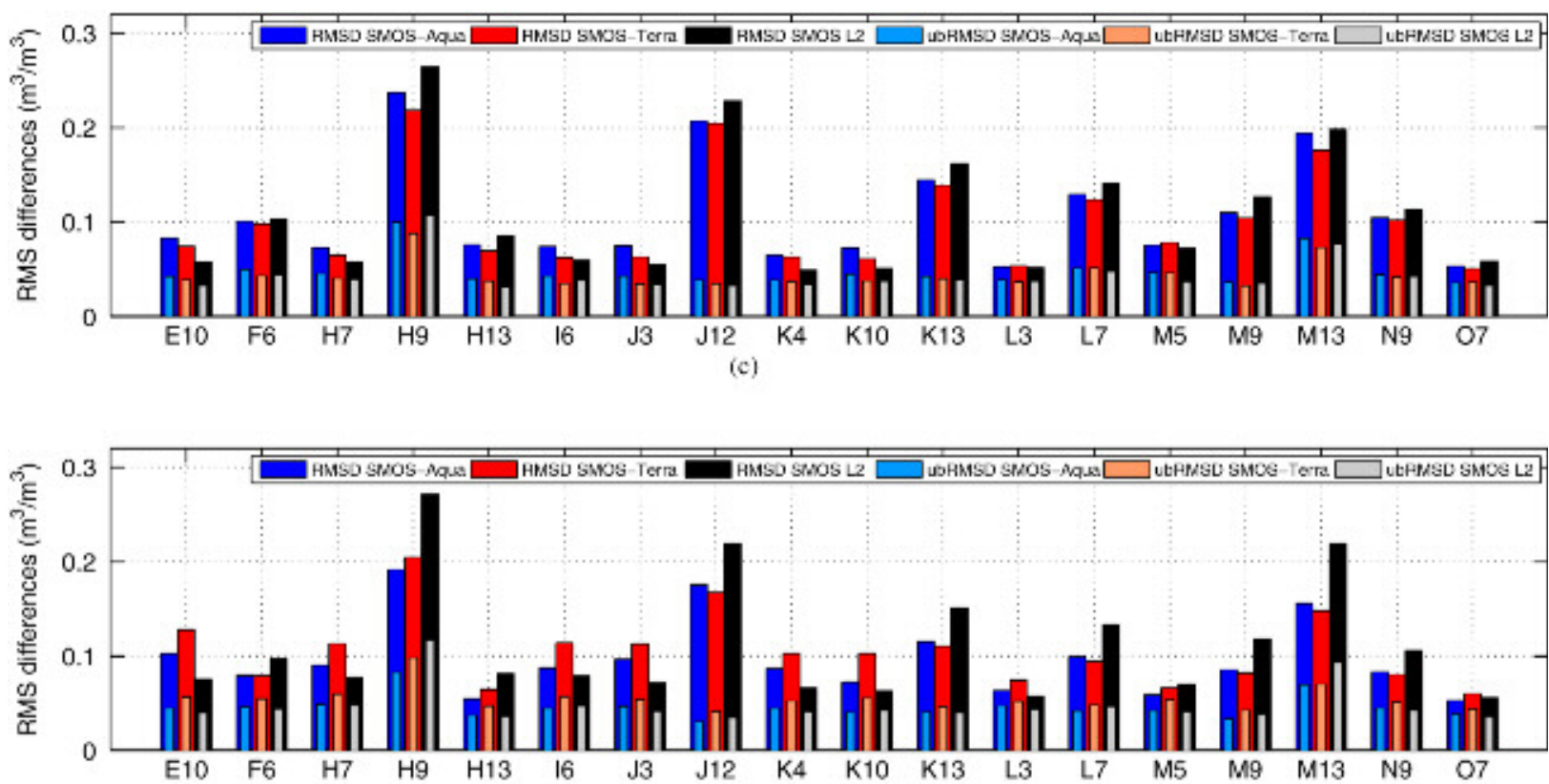

(d)

Fig. 3. Statistical results from the 2-year comparison of SMOS L2 and 1-km disaggregated SMOS soil moisture versus ground-based soil moisture at each REMEDHUS station. Correlation coefficient $\mathrm{R}$ obtained for (a) morning passes $[\mathrm{R} \approx 0.31-0.64$ (Aqua); $\mathrm{R} \approx 0.30-0.70$ (Terra); $\mathrm{R} \approx 0.33-0.73$ (L2)] and (b) afternoon passes $[\mathrm{R} \approx 0.49-0.73$ (Aqua); $\mathrm{R} \approx 0.37-0.78$ (Terra); $\mathrm{R} \approx 0.49-0.73$ (L2)]. RMS errors (RSMD and unbiased RMSD) obtained for (c) morning passes $\quad\left[R M S D \approx 0.05-0.24 \mathrm{~m}^{3} / \mathrm{m}^{3}\right.$ (Aqua); RMSD $\approx 0.05-0.22 \mathrm{~m}^{3} / \mathrm{m}^{3} \quad$ (Terra); RMSD $\approx 0.05-0.26 \mathrm{~m}^{3} / \mathrm{m}^{3}$ (L2)], and (d) afternoon passes $\left[R M S D \approx 0.05-0.19 \mathrm{~m}^{3} / \mathrm{m}^{3}\right.$ (Aqua); RMSD $\approx 0.06-0.20 \mathrm{~m}^{3} / \mathrm{m}^{3}$ (Terra); RMSD $\approx 0.06-0.27 \mathrm{~m}^{3} / \mathrm{m}^{3}$ (L2)]. Scores are presented for stations with significant correlations ( $\mathrm{p}$-values $<0.05$ ).

patterns (Fig. 5). In summer, only irrigated areas presented high soil moisture contents above $0.1 \mathrm{~m}^{3} / \mathrm{m}^{3}$, coinciding with the water supply at their most active growing period. Nevertheless, fluctuating values of the actual water content in those crops due to the high irrigation frequency (see annual evolution plot in Fig. 5) could not be captured using the remotely sensed observations, with a lower temporal resolution. For this use, soil moisture estimation failed in terms of a non significant $\mathrm{R}$ for all the four data sets (see Fig. 6). In autumn, soil moisture contents are similar and homogeneous for the different categories, with an increasing value for forest-pasture patches. Note that forestpasture is composed of evergreen species that naturally retain soil moisture. This effect is more evident in the winter map, when the soil moisture content of this land cover reaches its maximum (near $0.50 \mathrm{~m}^{3} / \mathrm{m}^{3}$ ) due to the cumulative rainfall (see Fig. 5). Indeed, forest-pasture is the category with higher R, even though the high water content observed in situ is underestimated in the downscaled maps (RMSD $\left.>0.2 \mathrm{~m}^{3} / \mathrm{m}^{3}\right)$. In spring, land 


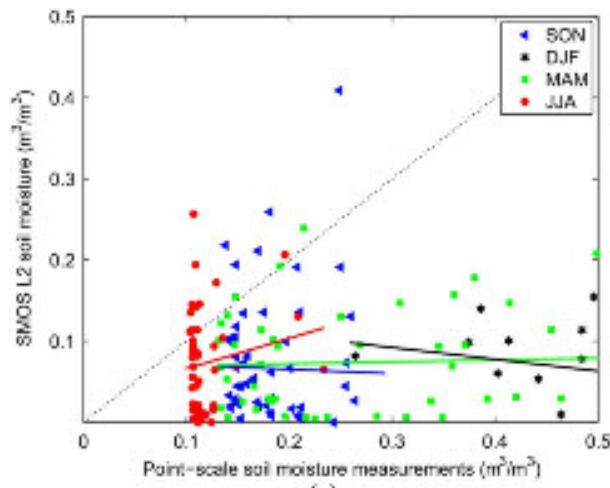

(a)

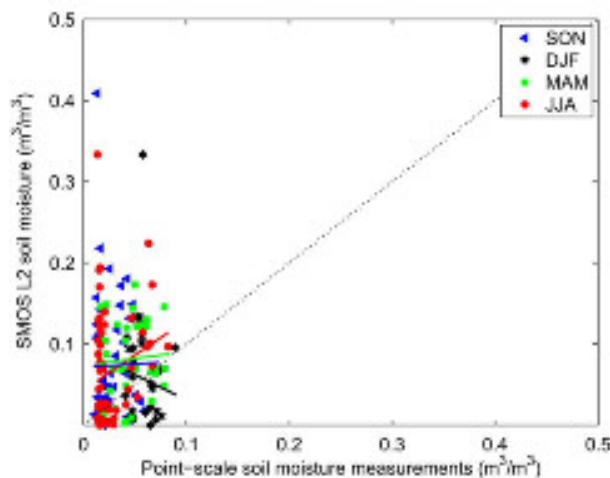

(c)

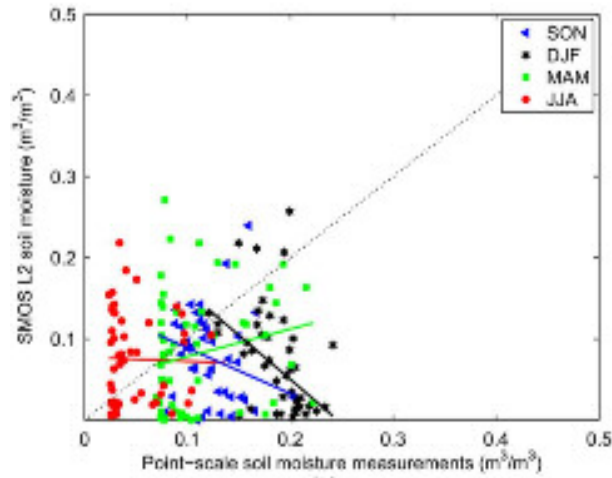

(c)

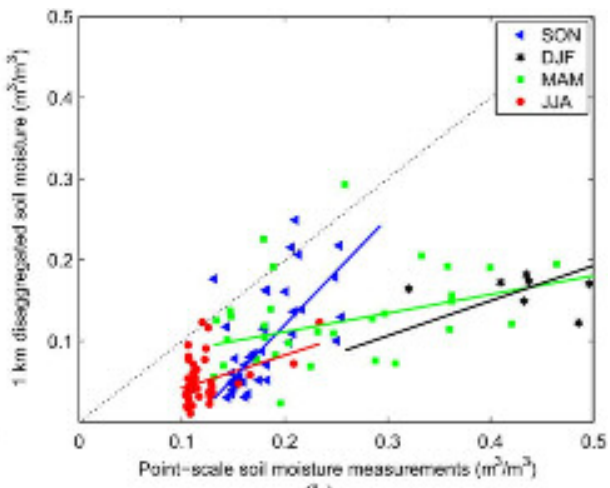

(b)

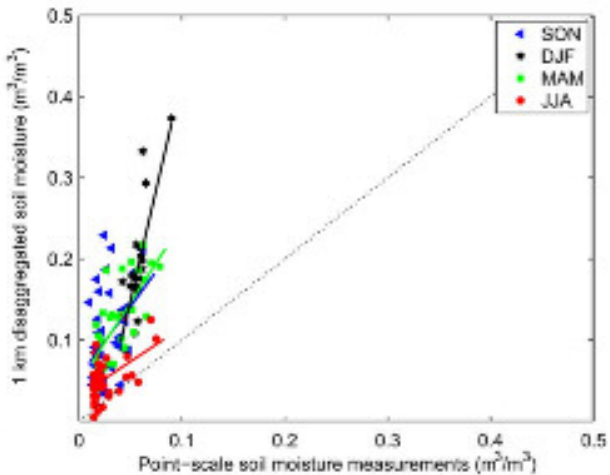

(d)

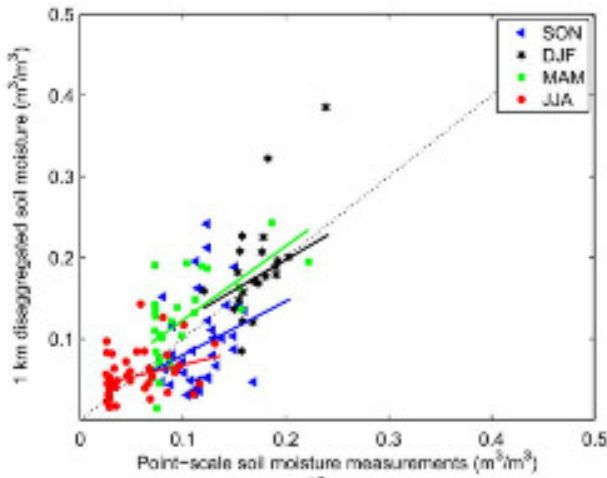

(f)

Fig. 4. Results of the seasonal analysis for the hydrological year starting in September 2010 (afternoon passes). Left column: Scatter plots of SMOS L2 soil moisture versus point-scale measurements at three representative REMEDHUS stations: (a) station M13 forest-pasture; (c) station K4 vineyard; and (e) station O7 rainfed cereals. Right column: scatter plots of 1-km SMOS-Terra disaggregated soil moisture versus point-scale measurements at (b) station M13 forest-pasture; (d) station K4 vineyard; and (f) station $\mathrm{O} 7$ rainfed cereals. Segments are linear fit of seasonal (3 months) data.

covers with no vegetation activity in this period (i.e., irrigated, fallow-unproductive, and vineyard) show the lower soil moisture contents due to evaporation by increasing temperature. Fig. 5 also evidences that soil moisture evolution in the downscaled maps is consistent: higher soil moisture in winter, due to accumulated rainfall and vegetation inactivity, lower soil moisture in summer. These results demonstrate disaggregated soil moisture estimates at $1 \mathrm{~km}$ compare well with the soil moisture dynamics of most generally used land uses with the exception of irrigated crops.

The purpose of using a vegetation index in the algorithm is to provide spatial patterns relating soil moisture and land uses (i.e., vegetation covers), which are spatially distributed according to the soil physical properties. The difference found in the downscaled soil moisture maps per land use category supports the use of NDVI in the algorithm. The use of other vegetation indices such as the NDVI or the Enhanced Vegetation Index should be explored in future research. More research can also be done on the NDVI response lag to antecedent precipitation and the varying lag-times between soil moisture and NDVI [39], [40], which were not taken into account here.

\section{DISCUSION AND CONCLUSION}

In this study, a microwave/optical disaggregation technique has been applied to combine SMOS and MODIS data into finescale soil moisture estimates over the Iberian Peninsula. Two years of dissagregated soil moisture maps at $1-\mathrm{km}$ spatial resolution have been compared to $0-5 \mathrm{~cm}$ ground-based measurements from the REMEDHUS soil moisture network in the central 
This article has been accepted for inclusion in a future issue of this journal. Content is final as presented, with the exception of pagination.

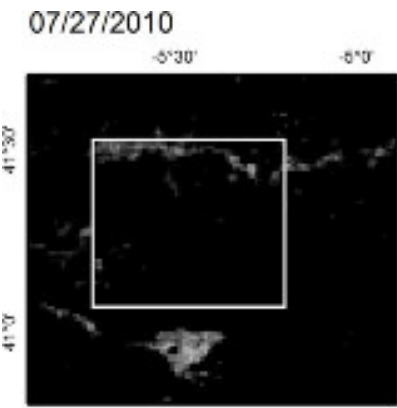

$$
0.1
$$
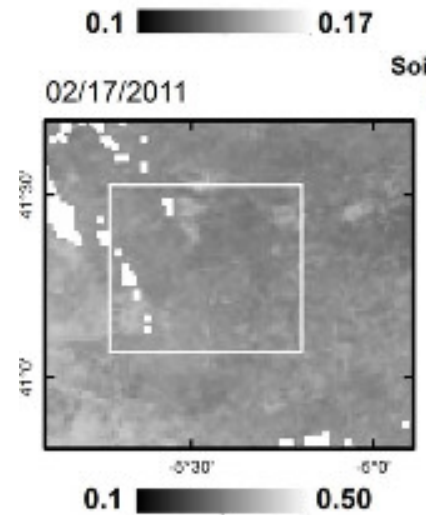

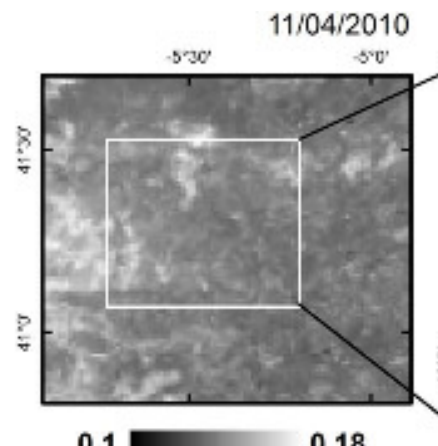

0.1

0.18

Soil moisture $\left(\mathrm{m}^{3 / 3} \mathrm{~m}^{3}\right)$
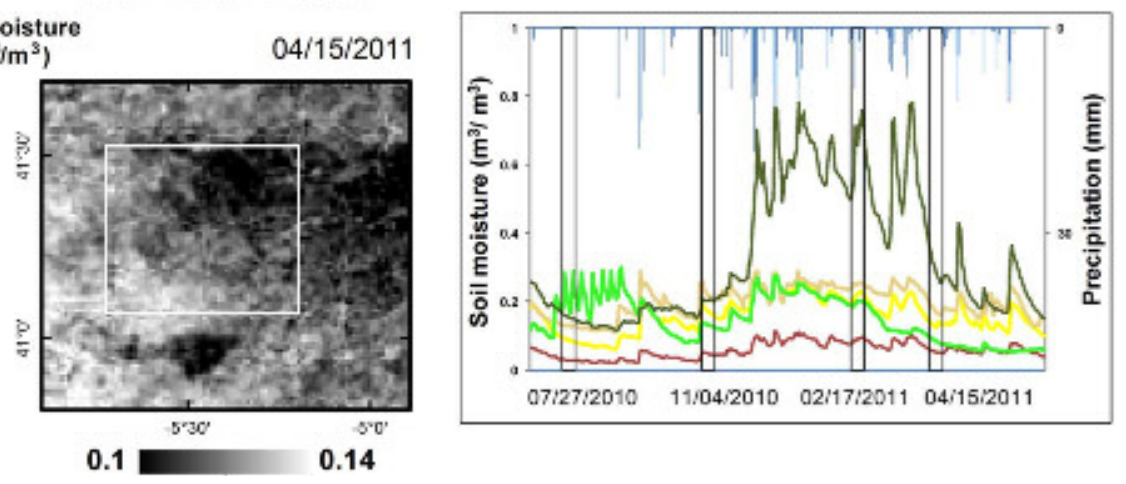

Fig. 5. Left: images of SMOS disaggregated soil moisture $\left(\mathrm{m}^{3} / \mathrm{m}^{3}\right)$ at 1-km resolution for selected dates covering the seasonal cycle of vegetation: July 27 , 2010 (summer), November 11, 2010 (autumn), February 17, 2011 (winter), and April 15, 2011 (spring). Top right: REMEDHUS land use/land cover map at 1-km spatial resolution. Bottom right: annual evolution plot of mean precipitation and mean ground-based soil moisture measurements per land use. Line colors correspond to those on the land use map legend.
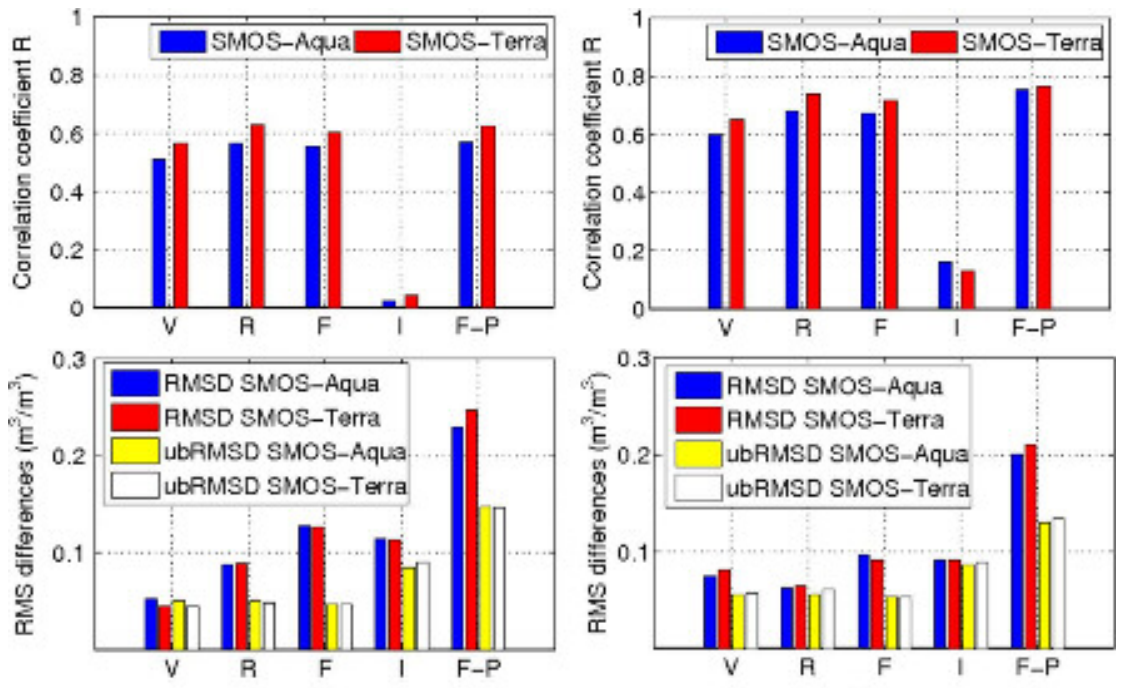

(a)

Fig. 6. Statistical results per land use for the hydrological year starting in September 2010. Correlation coefficient and RMS errors (RSMD and unbiased RMSD) of 1-km disaggregated SMOS soil moisture and ground-based soil moisture, aggregated per land use, for (a) morning and (b) afternoon passes. Land uses considered are vineyard (V), rainfed (R), fallow (F), irrigated (I), and forest-pasture(F-P). Correlations on the irrigated category are not significant (p-values $>0.05)$.

part of the Duero basin, Spain. Three matching strategies have been employed to evaluate the overall performance of the soil moisture downscaling algorithm and the quality of resulting high-resolution maps. The impact of using morning or afternoon passes and of using MODIS Terra or Aqua LST in the algorithm has also been analyzed.

A comparison at $40-\mathrm{km}$ resolution has been performed to ensure SMOS sensitivity at low resolution is preserved in the algorithm. Results show areal-averaged downscaled maps maintain SMOS L2 soil moisture errors and temporal correlation to in situ data, with $\mathrm{R}$ of $\sim 0.4 / 0.6$ for morning/afternoon passes, and ubRMSD of $\sim 0.03-0.04 \mathrm{~m}^{3} / \mathrm{m}^{3}$. The bias on SMOS L2 is reduced in the downscaled maps, with an improvement of $\sim 0.01-0.02$ in the RMSD. For afternoon passes, measures of skewness and kurtosis evidence that the downscaled estimates are closer to a normal distribution than SMOS L2 data.

The spatio-temporal correlation of downscaled soil moisture maps has been analyzed through comparison with point-scale 
observations at the REMEDHUS stations. Downscaled maps compare well with ground-based measurements, with an improved slope on the linear regression with respect to SMOS $\mathrm{L} 2$ (closer to the $1: 1$ line), same range of $\mathrm{R}(\approx 0.3-$ $0.7 / 0.4-0.8$ for morning/afternoon passes) and ubRMSD $\left(\approx 0.03-0.10 / 0.03-0.09 \mathrm{~m}^{3} / \mathrm{m}^{3}\right)$ and generally lower RMSD $\left(\approx 0.05-0.24 / 0.05-0.20 \mathrm{~m}^{3} / \mathrm{m}^{3}\right.$ for disaggregated maps, $\approx 0.05-0.26 / 0.05-0.27 \mathrm{~m}^{3} / \mathrm{m}^{3}$ for SMOS L2). The dynamic range of in situ soil moisture measurements is reproduced in the high-resolution maps, including stations with different mean soil wetness conditions. Results presented indicate the performance of the proposed downscaling algorithm is similar across seasons. This is an important difference with respect to the microwave/optical downscaling approaches based on evaporation efficiency, which have limited applicability in winter periods. Spatial correlation at a daily scale was only significant at a $95 \%$ level for 36 days, and ranged from 0.2 to 0.5 . This result, although not representative, suggests that soil moisture temporal variability may be better resolved than spatial variability in the downscaled maps. This is a key aspect that should be the subject of future research using dedicated field experiments or land surface models for validation.

When aggregating high-resolution maps and ground-based observations per land-use, spatial patterns related with vegetation phenology and seasons have been identified. Soil moisture evolution in the downscaled maps is consistent: higher soil moisture in winter, due to accumulated rainfall and vegetation inactivity, lower soil moisture in summer. Results demonstrate that the disaggregated soil moisture maps capture soil moisture dynamics of general land uses with the exception of irrigated crops.

Overall results indicate that better fine-scale soil moisture estimates should be expected from afternoon than from morning orbits. One possible reason for this is that the surface energy balance is more likely to be water-limited in the afternoon and therefore LST tightly coupled to soil moisture than in the morning. Then, the linking model in (1) would be more robust under afternoon than under morning ambient conditions. Another possible reason is the orbital difference present in SMOS $T_{B}[30]$. Since SMOS $T_{B}$ plays a central role in the algorithm, differences in $T_{B}$ between ascending and descending passes could have an impact in the resulting soil moisture maps.

In view of the results presented, the use of Terra LST in the algorithm is preferred. Nevertheless, downscaled maps using Aqua LST yielded broadly consistent results, which support the use of Aqua LST when Terra LST is not available (e.g., masked by clouds). The difference between Terra/Aqua LST data sets mainly lies in their acquisition times. LST is expected to be warmer in the early afternoon than the morning due to the link between maximum skin temperature and solar insolation peak time, therefore the Aqua LST afternoon pass (1.30 P.M.) is likely to be closer to the maximum daily LST than that acquired from Terra (10.30 A.м./10.30 P.м.) [41]. The use of thermal inertia (with embedded albedo) or daily temperature differences instead of absolute LST values would be subject of future research. Also, independent observations from Terra and Aqua could be combined to reduce random uncertainties in temperature estimations [20].
Out of all available optical sensors to downscale SMOS observations, we selected 1-km MODIS as auxiliary data to meet the temporal requirements of land hydrology applications. Yet the algorithm can potentially provide soil moisture maps at finer spatial resolutions than $1 \mathrm{~km}$, given higher spatial resolution optical data is used (e.g., 90-m ASTER). The transferability of results when using other optical platforms will require further validation. Also, it is important to note that the downscaling approach presented is dynamic and can be transported to any region.

This study has demonstrated the potential of using readily available data from SMOS and Terra/Aqua in-orbit satellites to provide global soil moisture estimates at fine spatial scales $(<1 \mathrm{~km})$. A downscaling scheme has been proposed as a key tool that could permit monitoring soil moisture at spatial and temporal resolutions previously not attained, and consequently transform the way we utilize our land and water resources through a better understanding of environmental systems.

\section{ACKNOWLEDGMENT}

The authors would like to thank the Remote Sensing Laboratory of Valladolid University for providing the Deimos-1 data used in this paper.

\section{REFERENCES}

[1] W. Krajewski et al., "A remote sensing observatory for hydrologic sciences: A genesis for scaling to continental hydrology," Water Resour. Res., vol. 42, 2006.

[2] J. Entin et al., "Temporal and spatial scales of observed soil moisture variations in extratropics," J. Geophys. Res., vol. 105, pp. 11 865-11877, 2000.

[3] J. Famiglietti, D. Ryu, A. Berg, M. Rodell, and T. Jackson, "Field observations of soil moisture variability across scales," Water Resour. Res., vol. 44, pp. 1-16, 2008.

[4] J. Martínez-Fernández and A. Ceballos, "Mean soil moisture estimation using temporal stability analysis," J. Hydrol., vol. 312, pp. 28-38, 2005.

[5] L. Brocca, T. Tullo, F. Melone, T. Moramarco, and R. Morbidelli, "Catchment scale soil moisture spatialtemporal variability," J. Hydrol., vol. 422423, no. 0, pp. 63-75, 2012.

[6] F. Ulaby, R. Moore, and A. Fung, Microwave Remote Sensing Active and Passive, Vol. 1 and 2. Norwood, MA, USA: Artech House, 1981.

[7] Y. Kerr et al., "The SMOS mission: New tool for monitoring key elements of the global water cycle," Proc. IEEE, vol. 98, no. 5, pp. 666-687, May 2010.

[8] J. Font et al., "SMOS: The challenging sea surface salinity measurement from space," Proc. IEEE, vol. 98, no. 5, pp. 649-665, May 2010.

[9] D. Entekhabi et al., "The soil moisture active passive (SMAP) mission," Proc. IEEE, vol. 98, no. 5, pp. 704-716, May 2010.

[10] V. Naeimi, K. Scipal, Z. Bartalis, S. Hasenauer, and W. Wagner, "An improved soil moisture retrieval algorithm for ers and metop scatterometer observations," IEEE Trans. Geosci. Remote Sens., vol. 47, no. 7, pp. 1999-2013, Jul. 2009.

[11] E. T. Engman, "Applications of microwave remote sensing of soil moisture for water resources and agriculture," Remote Sens. Environ., vol. 35, no. 23, pp. 213-226, 1991.

[12] J. Adegoke and A. Carleton, "Relations between soil moisture and satellite vegetation indices in the U.S. Corn Belt," Amer. Meteorol. Soc., vol. 3, pp. 395-405, 2002.

[13] X. Wang, H. Xie, H. Guan, and X. Zhou, "Different responses of MODISderived NDVI to root-zone soil moisture in semi-arid and humid regions," Hydrol. Earth Syst. Sci., vol. 340, pp. 12-14, 2007.

[14] M. T. Schnur, H. Xie, and X. Wang, "Estimating root zone soil moisture at distant sites using MODIS NDVI and EVI in a semi-arid region of southwestern USA," Ecol. Informat., vol. 5, no. 5, pp. 400-409, 2010. 
[15] M. Owe, R. de Jeu, and J. Walker, "A methodology for surface soil moisture and vegetation optical depth retrieval using the microwave polarization difference index," IEEE Trans. Geosci. Remote Sens., vol. 39, no. 8, pp. 1643-1654, Aug. 2001.

[16] T. Carlson, "An overview of the "triangle method" for estimating surface evapotranspiration and soil moisture from satellite imagery," Sensors, vol.7, pp. $1612-1629,2007$

[17] O. Merlin et al., "Self-calibrated evaporation-based disaggregation of SMOS soil moisture: An evaluation study at $3 \mathrm{~km}$ and $100 \mathrm{~m}$ resolution in Catalunya, Spain," Remote Sens. Environ., vol. 130, pp. 25-38, 2012.

[18] M. Piles, D. Entekhabi, and A. Camps, "A change detection algorithm for retrieving high-resolution soil moisture from SMAP radar and radiometer observations," IEEE Trans. Geosci. Remote Sens., vol. 47, no. 12, pp. 4125-4131, Dec. 2009

[19] N. Das, D. Entekhabi, and E. Njoku, "Algorithm for merging SMAP radiometer and radar data for high resolution soil moisture retrieval," IEEE Trans. Geosci. Remote Sens., vol. 49, no. 5, pp. 1504-1512, May 2011.

[20] O. Merlin, A. A. Bitar, J. Walker, and Y. Kerr, "An improved algorithm for disaggregating microwave-derived soil moisture based on red, near-infrared and thermal-infrared data," Remote Sens. Environ., vol. 114, pp. 23052316, 2010.

[21] M. Piles et al., "Downscaling SMOS-derived soil moisture using MODIS visible/infrared data," IEEE Trans. Geosci. Remote Sens., vol. 49, no. 9, pp. 3156-3166, Sep. 2011.

[22] O. Merlin et al., "Disaggregation of SMOS soil moisture in Southeastern Australia," IEEE Trans. Geosci. Remote Sens., vol. 50, no. 5, pp. 15561571, May 2012.

[23] M. Piles, M. Vall-llossera, L. Laguna, and A. Camps, "A downscaling approach to combine SMOS multi-angular and full-polarimetric observations with MODIS VIS/IR data into high resolution soil moisture maps," in Proc. IEEE Int. Geosci. Remote Sens. Symp. (IGARSS'12), 2012, pp. 1247-1250.

[24] M. Piles et al., "On the synergy of smos and terra/aqua modis: High resolution soil moisture maps in near real-time," in Proc. IEEE Int. Geosci. Remote Sens. Symp. (IGARSS'13), Jul. 2013, pp. 3423-3426.

[25] N. Sánchez, J. Martínez-Fernández, A. Scaini, and C. Pérez-Gutiérrez, "Validation of the SMOS L2 soil moisture data in the REMEDHUS Network (Spain)," IEEE Trans. Geosci. Remote Sens., vol. 50, no. 5, pp. 1602-1611, May 2012.

[26] A. Ceballos, K. Scipal, W. Wagner, and J. Martínez-Fernández, "Validation of ERS scatterometer-derived soil moisture data in the central part of the Duero basin, Spain," Hydrol. Processes, vol. 19, pp. 1549-1566, 2005.

[27] L. Brocca et al., "Soil moisture estimation through ASCAT and AMSR-E sensors: An intercomparison and validation study across Europe," Remote Sens. Environ., vol. 115, no. 12, pp. 3390-3408, 2011.

[28] Deimos Imaging S. L. (2013). Our Satellite Deimos-1 [Online]. Available: http://www.deimos-imaging.com/technology/our-satellite-deimos-1

[29] K. McMullan et al., "SMOS: The payload," IEEE Trans. Geosci. Remote Sens., vol. 46, no. 3, pp. 594-605, Mar. 2008.

[30] R. Oliva et al., "SMOS calibration and instrument performance after one year in orbit," IEEE Trans. Geosci. Remote Sens., vol. 51, no. 1, pp. 654670, Jan. 2013.

[31] K. Wang, S. E. Franklin, and X. Guo, "The applicability of a small satellite constellation in classification for large-area habitat mapping: A case study of dmc multispectral imagery in west-central alberta," Can. J. Remote Sens., vol. 36, no. 6, pp. 671-681, 2010.

[32] B. Markham and J. Baker, "Landsat-MSS and TM post-calibration dynamic ranges, atmospheric reflectance and at-satellite temperature," EOSAT Landsat, Earth Observation Satellite Company, Lanham, MD, USA, Tech. Rep. no. 1, 1986.

[33] G. Crowley, "DCM data product manual, DCM international image ltd," Guilford, U.K., Tech. Rep. no. 0115056, 2010.

[34] N. Sánchez, J. Martínez-Fernández, M. Rodríguez-Ruiz, E. Torres, and A. Calera, "A simulation of soil water content based on remote sensing in a semi-arid mediterranean agricultural landscape," Spanish J. Agric. Res., vol. 10 , no. 2,2012 , pp. 521-532.

[35] A. Loew and F. Schlenz, "A dynamic approach for evaluating coarse scale satellite soil moisture products," Hydrol. Earth Syst. Sci., vol. 15, pp. 75-90, 2011.

[36] C. Albergel et al., "Evaluation of remotely sensed and modelled soil moisture products using global ground-based in situ observations," Remote Sens. Environ., vol. 118, pp. 215-226, 2012.

[37] W. Crow et al., "Upscaling sparse ground-based soil moisture observations for the validation of coarse-resolution satellite soil moisture products," Rev. Geophys., vol. 50, p. RG2002, 2012.
[38] D. Entekhabi, R. Reichle, R. Koster, and W. Crow, "Performance metrics for soil moisture retrievals and applications requirements," J. Hydrometeorol., vol. 11, pp. 832-840, 2010.

[39] S. Park, J. J. Feddema, and S. L. Egbert, "Impacts of hydrologic soil properties on drought detection with MODIS thermal data," Remote Sens Environ., vol. 89, no. 1, pp. 53-62, 2004.

[40] K. P. Price, P. M. Rich, and J. Wang, "Spatial patterns of NDVI in response to precipitation and temperature in the central great plains," Int. J. Remote Sens., vol. 22, pp. 3827-3844, 2001.

[41] N. C. Coops, D. C. Duro, M.A. Wulder, and T. Han, "Estimating afternoon MODIS land surface temperatures (LST) based on morning MODIS overpass, location and elevation information," Int. J. Remote Sens., vol. 28, pp. 2391-2396, 2007.

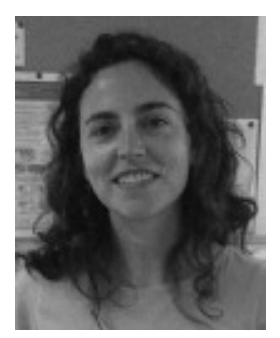

María Piles (S'05-M'11) was born in Valencia, Spain, in 1982. She received the M.S. and Ph.D. degrees in telecommunication engineering from the Universitat Politècnica de Valncia (UPV), València, Spain, in 2005, and Universitat Politècnica de Catalunya (UPC), Barcelona, Spain, in 2010, respectively.

In 2008, she was a Visiting Ph.D. student with the Department of Civil and Environmental Engineering, Massachusetts Institute of Technology, Boston, MA, USA. In 2010, she joined the Department of Civil and Environmental Engineering, University of Melbourne, Melbourne, Australia, as a Research Fellow. Since 2011, she is a Research Scientist at UPC and is based at the SMOS Barcelona Expert Center. Her research interests include remote sensing for Earth observation, with special emphasis in microwave radiometers, radars and VIS/IR sensors, retrieval of soil moisture and vegetation parameters, development of downscaling algorithms, and data fusion techniques. She has participated in eight research projects funded by national and international agencies, mainly related to the ESA's SMOS and the NASA's SMAP missions.

Dr. Piles received the Med-Storm Prize for Young Researchers in the Plinius conference (2011) and the UPC special doctoral award in Information Technology and Communication (2012). Since 2012, she is the Secretary of the IEEE Geoscience and Remote Sensing Society (GRSS) Spanish chapter. She has published 12 papers in peer-reviewed journals, and more than 60 international conference presentations.

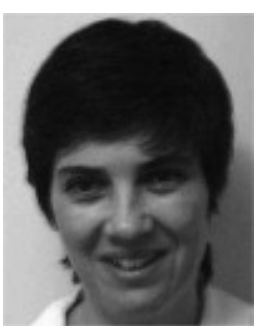

Nilda Sánchez (M’11) was born in Córdoba, Spain She received the M.Sc. and Ph.D. degrees in cartographic engineering from the University of Salamanca (USAL), Salamanca, Spain, in 2002 and 2009, respectively. She also received the Master degree in geographical information systems from the University of Girona, Spain, in 2000

She is an Associate Professor since 1994 in the University of Salamanca, and participated at several national and international research programmes from the Spanish Ministry of Science and Research, the European Comission and the European Space Agency. She joined HIDRUS (Water Resources Research Group), Centro Hispano Luso de Investigaciones Agrarias (CIALE), University of Salamanca, in 2006. The activities of this group are devoted to hydrological and agricultural applied research. She has been involved in SMOS Cal/Val activities since its launch and in the development of advanced products and applications of soil moisture. Her research interests include modeling of soil moisture, evapotranspiration and vegetation parameters supported by remotely sensed data.

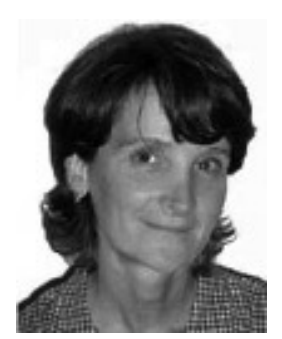

Mercè Vall-llossera (SM'99) received the M.S. and $\mathrm{Ph} . \mathrm{D}$. degrees in telecommunications engineering from the Universitat Politècnica de Catalunya (UPC), Barcelona, Spain, in 1990 and 1994, respectively.

She has been lecturing and doing research with the Department of Signal Theory and Communications, UPC, from 1990 to 1997, as an Assistant Professor and from 1997 to present, as an Associate Professor. She spent a sabbatical year with the Concordia University, Montreal, QC, Canada, with the scholarship of the "Programme Québécois de Bourses dexcellence"(1996-1997): "Stages de Formation postdoctorale au Québec pour jeunes diplomés étrangers" applying the FDTD method in the analysis of the effect of mobile telephone to the body. She has been participating in several projects for the preparation of the SMOS mission by ESA. Her research interests include passive remote sensing and retrieval of geophysical parameters from radiometric measurements. 


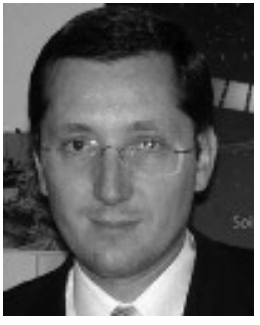

Adriano Camps (S'91-A'97-M'00-SM'03-F'11) was born in Barcelona, Spain, in 1969. He received the M.S. and Ph.D. degrees in telecommunications engineering from the Universitat Politècnica de Catalunya (UPC), Barcelona, Spain, in 1992 and 1996, respectively.

In 1991 to 1992, he was with the ENS des Télécommunications de Bretagne, France, with an Erasmus Fellowship. Since 1993, he has been with the Electromagnetics and Photonics Engineering Group, Department of Signal Theory and Communications, UPC, where he was an Assistant Professor, an Associate Professor in 1997, and a Full Professor since 2007. In 1999, he was on sabbatical leave with the Microwave Remote Sensing Laboratory, University of Massachusetts, Amherst, MA, USA. Since 1993, he has been deeply involved in the European Space Agency SMOS Earth Explorer Mission, and since 2001 on the use of GNSS-R techniques to perform the sea state correction needed to retrieve salinity from radiometric observations.

Dr. Camps has received a number of awards for his research and teaching activies, among which the Research Distinction of the Generalitat de Catalunya (2002) for contributions to microwave passive remote sensing; the European Young Investigator Award (2004) of the European Science Foundation, the ICREA Academia award (2009), and the 1st (2000) and 7th (2010) Duran Farell Awards. He has published more than 125 peer-reviewed journal papers, and more than 250 international conference presentations.

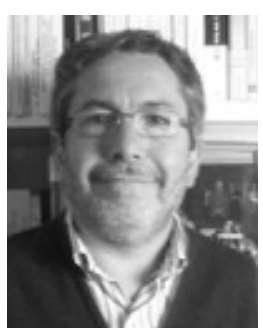

José Martínez-Fernández was born in Moratalla, Spain, in 1961. He received the B.S. (Degree Award), the M.S. degree in water science and technology, and the Ph.D. degree in physical geography from the Universidad de Murcia (UM), Murcia, Spain, in 1985, 1991, and 1992, respectively.

He was a Research Fellowship (1988-1992) and Junior Researcher (1992-1994) with the Department of Geography, UM. In 1995, he was an Assistant Professor with the Department of Geography, Universidad de Salamanca (USAL), Salamanca, Spain, where he has been an Associate Professor since 1997. Currently, he is the Principal Investigator (PI) of the Water Resources Research Group, Centro Hispano Luso de Investigaciones Agrarias (CIALE), USAL. He has been PI in eighteen national and international (Regional and Spanish Research Programmes, European Union, European Space Agency) research projects and collaborator in twelve.

Dr. Martínez-Fernández has been member of the Spanish National Biodiversity, Earth Sciences and Global Change Programme R\&D Projects Selection Committee. $\mathrm{He}$ is author or coauthor of 136 publications.

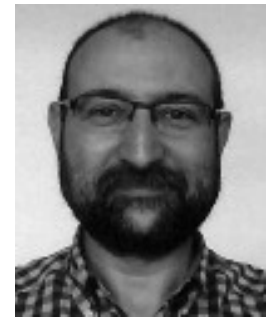

Justino Martínez was born in Girona, Spain, in 1966. $\mathrm{He}$ received the B.Sc. and Ph.D. degrees in physics from Autonomous University of Barcelona, Barcelona, Spain, in 1991 and 1995, respectively.

He is currently working as a Scientific Programmer in the Physical Oceanography Department, Institut de Ciencies del Mar, Consejo Superior de Investigaciones Cientificas, Barcelona, Spain. Currently, he is developing methods and tools to retrieve sea surface salinity from brightness temperature. He is also centered on the so-called forward model and inversion methods.

Dr. Martínez is also a member of the Soil Moisture and Ocean Salinity (SMOS) Barcelona Expert Centre, Barcelona, Spain, and he is involved in the L3 and L4 SMOS products generation.

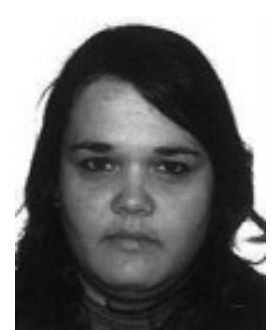

Verónica González-Gambau was born in Huesca, Spain, in 1981. She received the M.S. and Ph.D. degrees in telecommunication engineering from the Universitat Politècnica de Catalunya (UPC), Barcelona, Spain, in 2006 and 2012, respectively.

In 2006, she joined the Passive Remote Sensing Group of the Signal Theory and Communications Department, UPC, where she was involved in the Soil Moisture and Ocean Salinity (SMOS) payload onground characterization in the framework of SMOS precommissioning activities. She was also collaborating with the SMOS Level 1 software development and data analysis of the microwave imaging radiometer by aperture synthesis (MIRAS) instrument validation campaigns. Since 2007, she is a member of the SMOS Barcelona Expert Centre, first as a UPC Researcher and currently as a Research Scientist with the Institut de Ciències del Mar (ICM-CSIC), where she is responsible for the advanced Level 1 error correction techniques and in-orbit validation procedures. Currently, she is working on the development of algorithms for the SMOS brightness temperatures improvement and assessing the impact of these techniques on the quality of the geophysical retrievals. 